\title{
THE EFFECT OF HEATING WITH ALKALI ON THE CALORIGENIC ACTIVITY OF DESICCATED THYROID AND OF THYROXINE ${ }^{1}$
}

\author{
By WILLARD O. THOMPSON, PHEBE K. THOMPSON, SAMUEL G. TAYLOR, III,² \\ AND LOIS F. N. DICKIE \\ (From the Department of Medicine, Rush Medical College of the University of Chicago, and \\ the Presbyterian and Cook County Hospitals, Chicago)
}

(Received for publication September 23, 1936)

Since thyroxine is usually prepared for intravenous administration by heating with alkali, it seemed desirable, for purposes of comparison, to observe the effect of this procedure on desiccated thyroid. It became apparent at once that it destroyed most of the gland's activity, whereas thyroxine was unaffected by the same treatment (1, 2 ). This finding took on added interest because heating with alkali is an important step in obtaining thyroxine from the gland.

It was later noted that Roos (3), on the basis of reduction in the size of goiter in man, and Cameron and Carmichael (4), on the basis of the rate of growth and hypertrophy of organs in rats, had reported that heating with potassium and sodium hydroxide destroys a large part of the activity of iodothyrin and iodothyroglobulin, respectively. Their methods of assay were, of course, unreliable. Oswald (5) noted the instability of the active thyroid protein and avoided heat when using alkaline hydrolysis. Kendall and Simonsen (6) did employ heat in extracting thyroxine and were sometimes unable to isolate any from desiccated glands which possessed physiological activity before alkaline hydrolysis. In contrast with these observations, Leland and Foster (7) have found that after heating with $2 \mathrm{~N}$ sodium hydroxide for eighteen hours, eighty-five per cent of the iodine combined as thyroxine can be extracted with butyl alcohol, suggesting that little if any destruction has occurred.

\section{METHOD}

The total calorigenic response to the oral administration of a certain dose of desiccated thyroid $^{3}$ or of thyroxine ${ }^{4}$ was observed in patients

${ }^{1}$ Brief references to this work have been previously published $(1,2)$.

2 Squibb Research Fellow.

8 The desiccated thyroid, unless otherwise noted, was in the form of powder which had been defatted with benzene and was kindly supplied by Dr. Klein of the Wilson Lab- with myxedema. (The standard dose contained $6.5 \mathrm{mgm}$. of iodine, the amount in $10 \mathrm{mgm}$. of thyroxine.) Then material from the same lot was heated for different lengths of time with approximately normal sodium hydroxide ${ }^{5}$ (Table I), usually in the proportion of $5 \mathrm{cc}$. of alkali to $6.5 \mathrm{mgm}$. of iodine. The effects of the same procedure without heating, of heating with a weaker solution of alkali, and of heating with distilled water were also observed. The heating was carried out in a small beaker on a water bath. Although the solution was brought up to volume at frequent intervals, some variation in the concentration of alkali occurred. After suitable preparation, the material was diluted with a total of from 500 to $800 \mathrm{cc}$. of distilled water and administered slowly by mouth over a period of about two hours.

In five of eight patients in whom the effect of heating desiccated thyroid with alkali was observed, the heated and unheated doses contained the same amounts of iodine; in one, the heated dose contained only half as much and in two, twice as much. In two of the patients (Mrs. M. M., Figure 2 and Mrs. M. K., Figure 3) in whom the amounts of iodine in the heated and unheated doses were different, data have been included on the effects of another lot of desiccated thyroid which was given in doses containing more nearly the same amount of iodine as the heated doses. These additional data have been recorded because it has been found essential to compare doses on the basis of similar amounts of iodine, owing to some diminution in effect per unit of iodine with increasing doses (2).

oratories. Four lots were used-three lots of hog thyroid and one of the dried gland from a patient with exophthalmic goiter.

4 The synthetic thyroxine of Hoffmann-La Roche.

5 The solution actually used was $1.14 \mathrm{~N}$ sodium hydroxide. 
W. O. THOMPSON, P. K. THOMPSON, S. G. TAYLOR, III, AND L. F. N. DICKIE

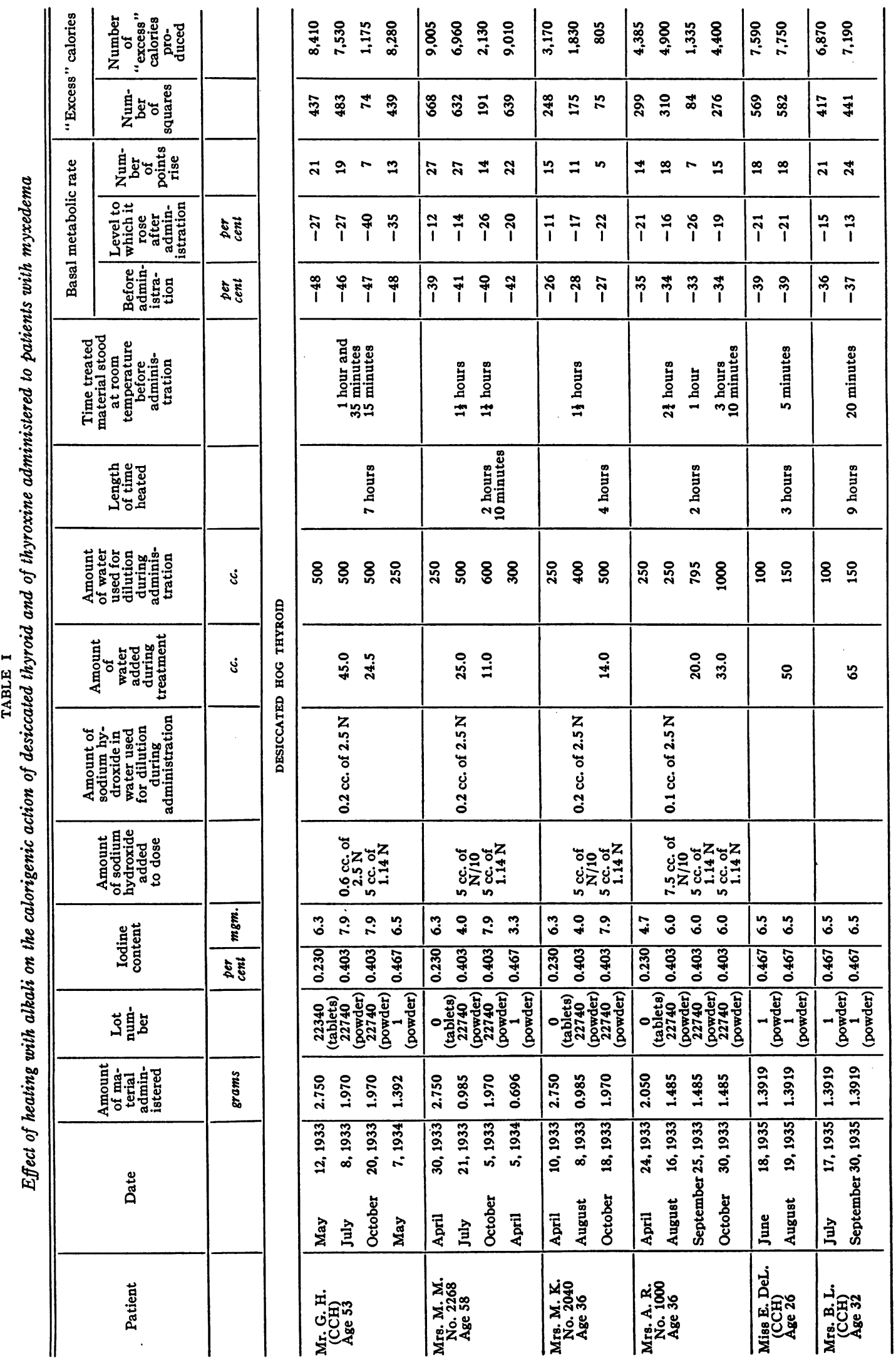




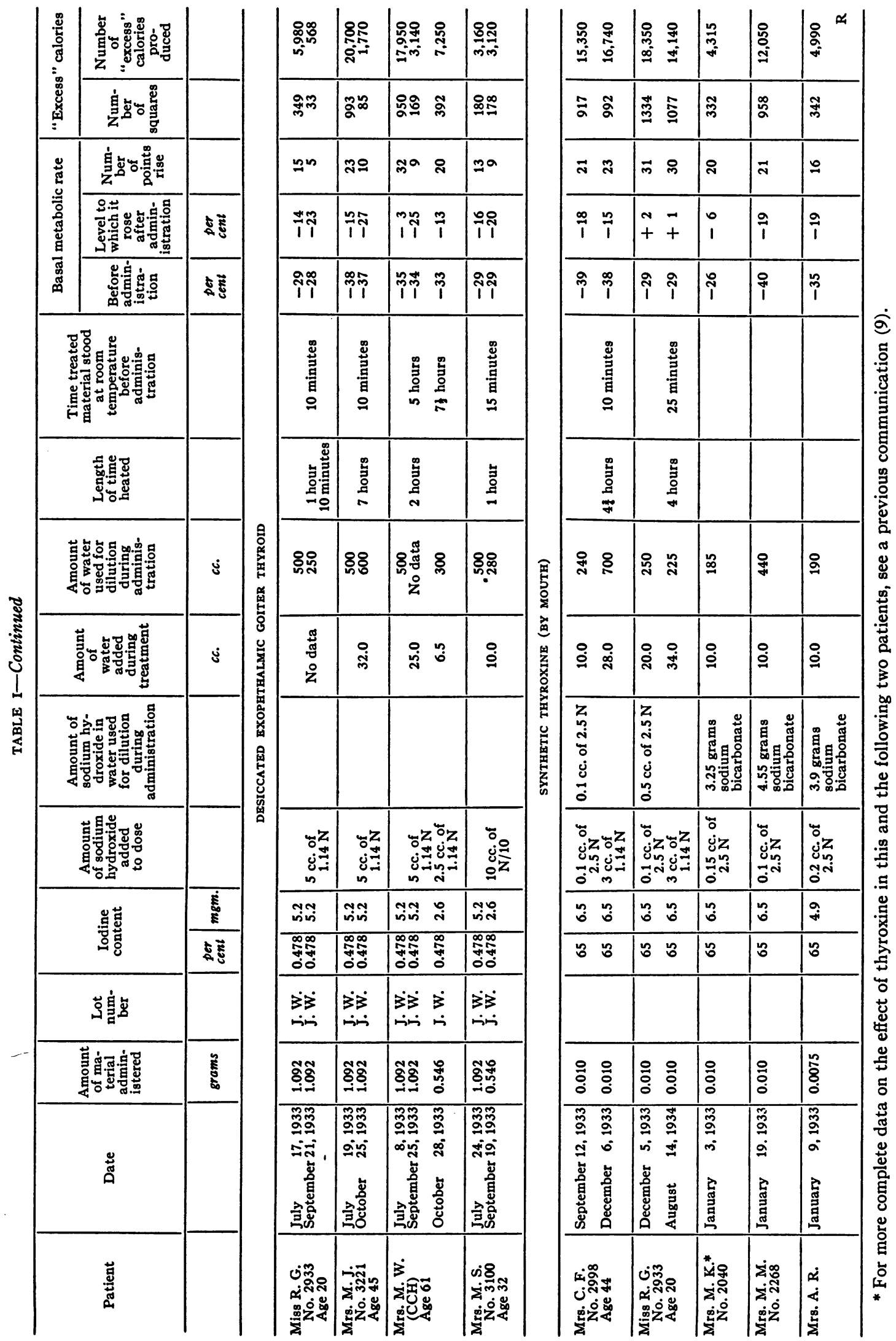


W. O. THOMPSON, P. K. THOMPSON, S. G. TAYLOR, III, AND L. F. N. DICKIE

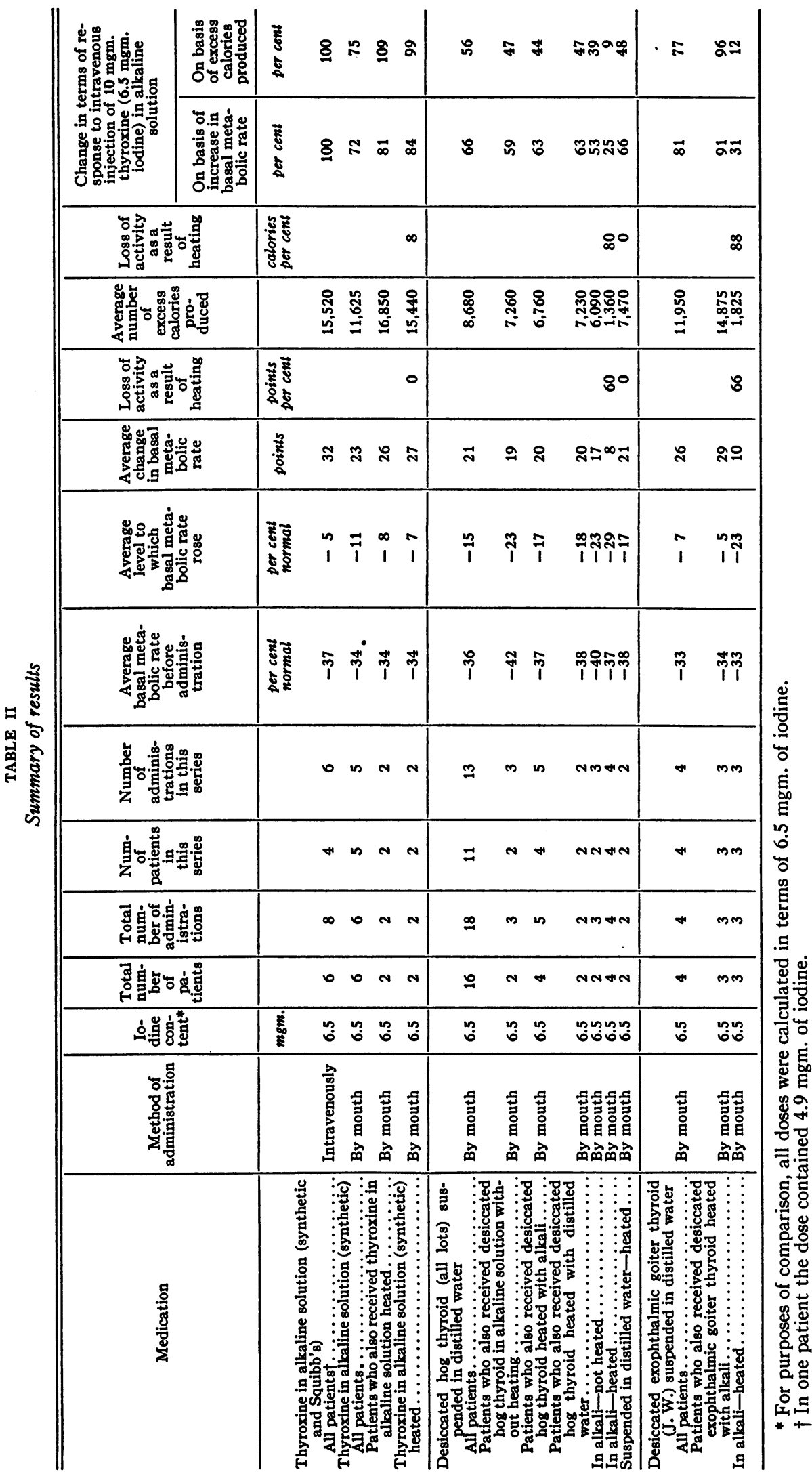


EFFECT OF HEATING WITH ALKALI ON THYROID

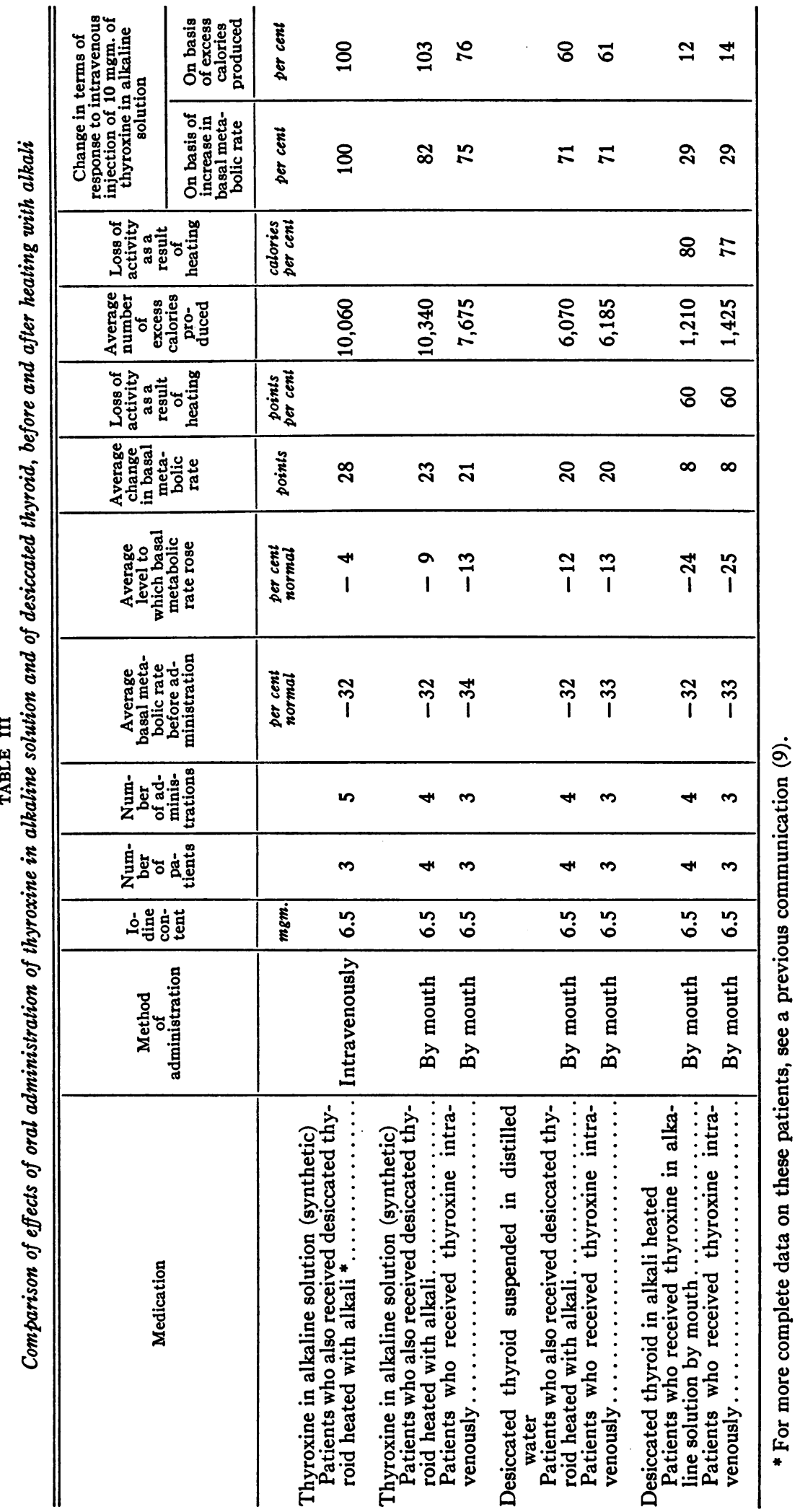


Excess calories were calculated by a method previously described $(8,9)$.

DATA

\section{Effect of heating desiccated thyroid with alkali}

The data are recorded in Tables I, II and III and in Figures 1 to 8 . The results may be summarized as follows.

1. After heating with approximately normal sodium hydroxide for from one to seven hours, desiccated thyroid loses about three-fifths of its calorigenic activity, on the basis of the number of points increase in metabolism; and about fourfifths of it, on the basis of the number of extra calories produced (Table II).

2. This loss of activity appears to be about as great at the end of one hour as at the end of seven hours (Miss R. G., Figure 5, compared with Mr. G. H., Figure 1, and Mrs. M. J., Figure 6).

3. The strength of the alkali appears to be important. In the one instance in which heating

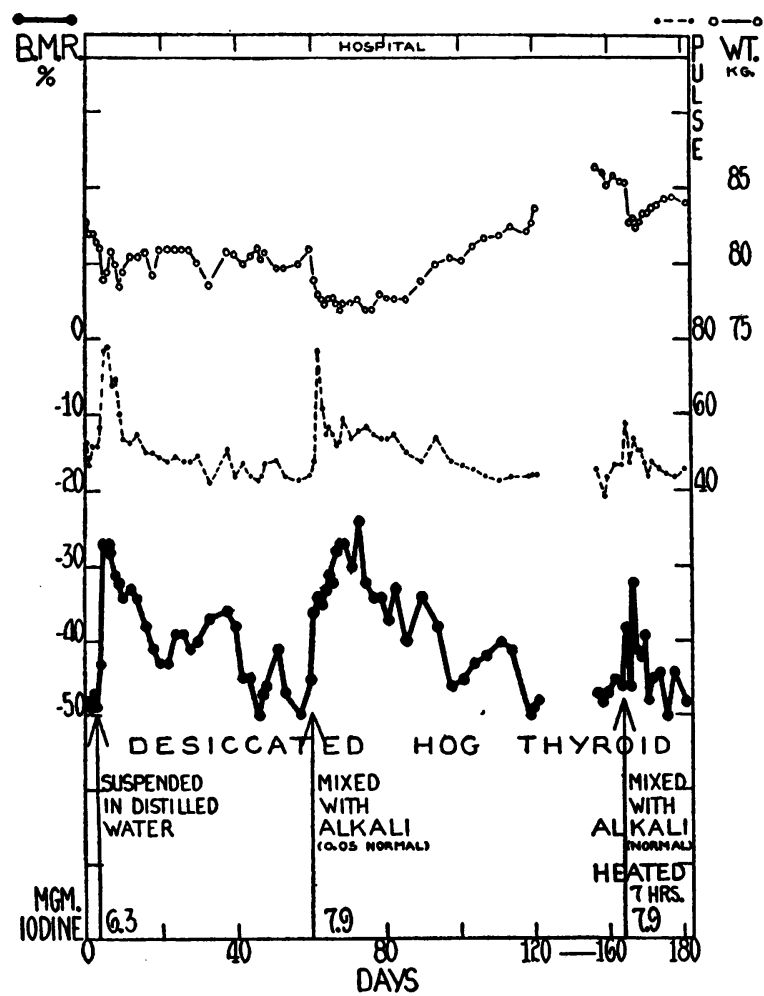

Fig. 1. Mr. G. H. Comparative Effects of the Oral Administration of Desiccated Hog Thyroid Suspended in Distilled Water, and Mixed with Alkali, with aNd without Heating with alkali did not cause loss of activity (Mrs. M. S., Figure 8) the alkali used was $0.1 \mathrm{~N}$ instead of $1 \mathrm{~N}$.

4. Allowing the dried gland to stand in $1 \mathrm{~N}$ sodium hydroxide without heating did not cause a significant loss of activity (Mr. G. H., Figure 1 ; Mrs. M. M., Figure 2; Mrs. M. K., Figure 3; Mrs. A. R., Figure 4; Mrs. M. W., Figure 7).

5. The relative loss of activity in the exophthalmic goiter gland as a result of heating with alkali appeared to be about the same as in the hog thyroid (Table II; and Figures 5 to 8 compared with Figures 1 to 4 ).

Repeated administrations of the same dose of desiccated thyroid or of thyroxine to the same patient produce about the same calorigenic response. Therefore, the slight response to thyroid which had been heated with alkali cannot be explained on the basis of the development of a tolerance.

The question arises as to whether the calorigenic effects of different preparations should be compared on the basis of the amount of increase in the basal metabolism or on the number of extra calories produced, the latter showing approximately a twenty per cent greater loss of activity on the average than the former. The number of extra calories is calculated from a curve denoting the change in metabolism from the time a given preparation is administered until its effect has completely disappeared. There are reasons for believing that the total response is important in comparing the action of different compounds. For example, it would be unfair to compare the effects of dinitrophenol and thyroxine on the basis of the amount of increase in basal metabolism, because the effect of a single dose of dinitrophenol lasts for only three or four days, while that of a single dose of thyroxine may last for as long as eighty days (2).

\section{Effect of heating desiccated thyroid with distilled water}

In contrast with the marked loss of calorigenic activity produced by heating desiccated thyroid with alkali, it may be seen from Tables I and II and Figures 9 and 10 that heating 'desiccated thyroid with distilled water for three hours and nine hours respectively produced no loss of activity. 


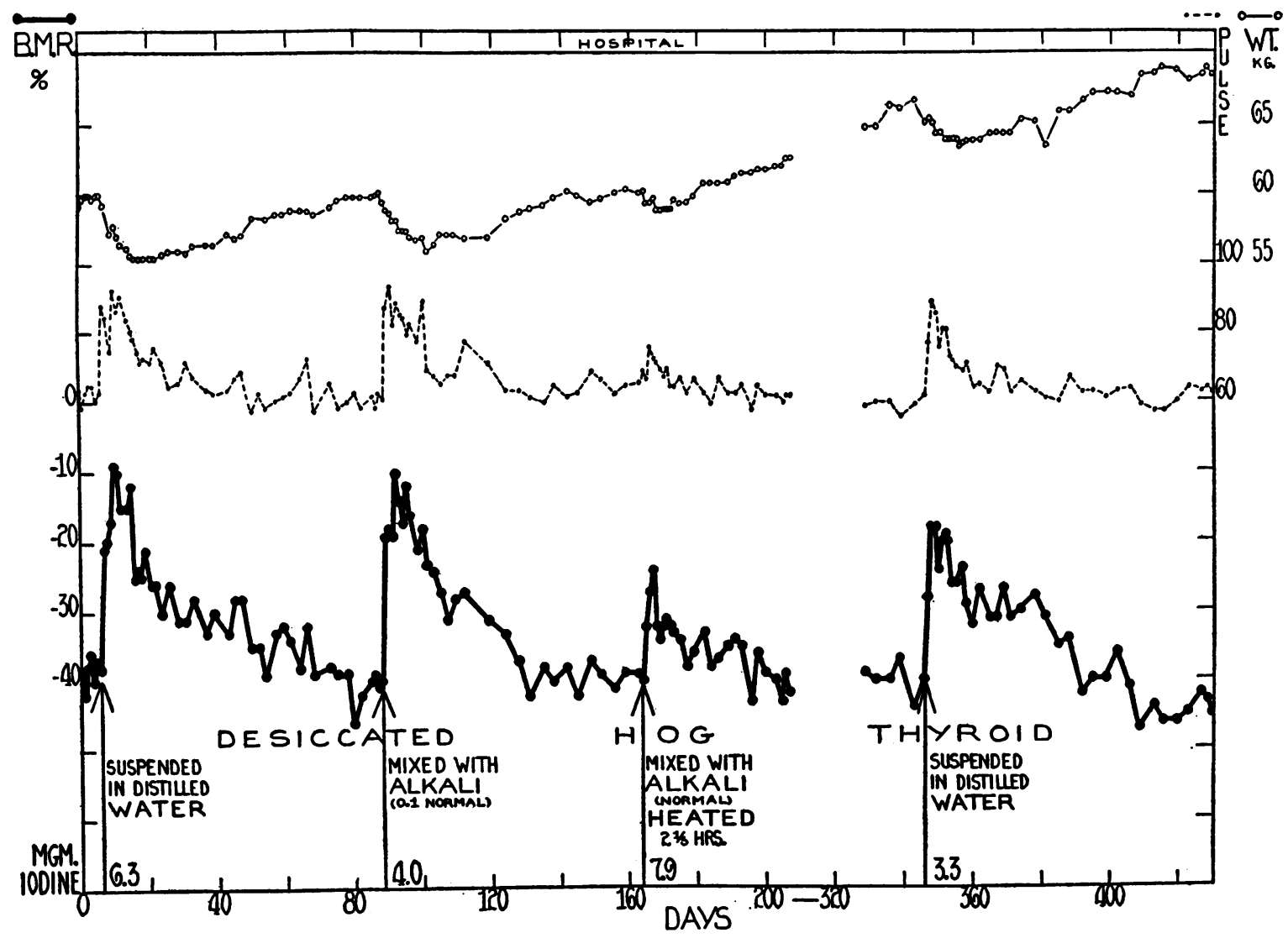

Fig. 2. Mrs. M. M. Lab. No. 2268. Also Showing the Comparative Effects of the Oral Administration of Desiccated Hog Thyroid Suspended in Distilled Water, and Mixed with Alkali, with and without HeATing

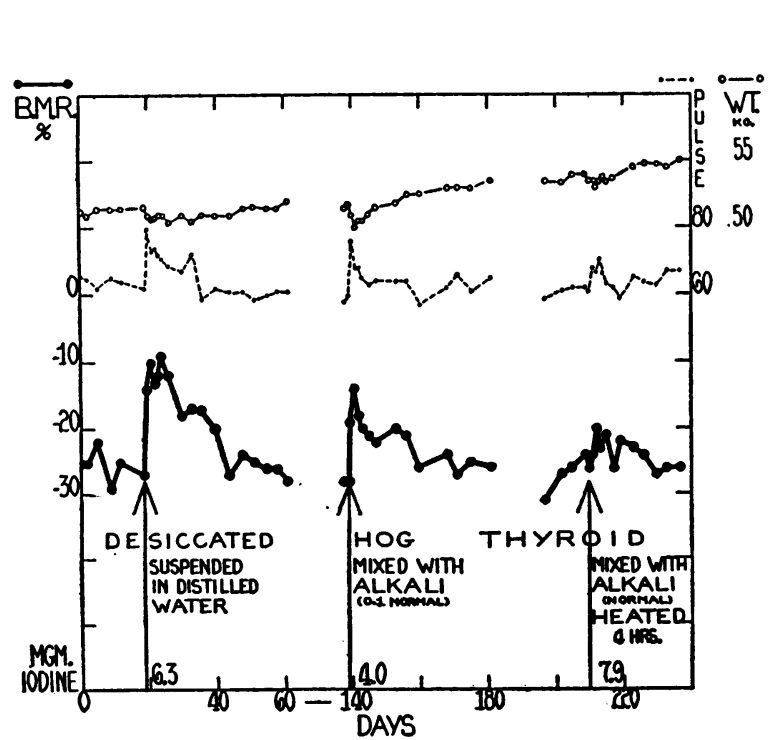

Fig. 3. Mrs. M. K. Lab. No. 2040. Also Showing the Comparative Effects of the Oral Administration of Desiccated Hog Thyroid Suspended in Distilled Water, and Mixed with Alkali, with aNd without Heating

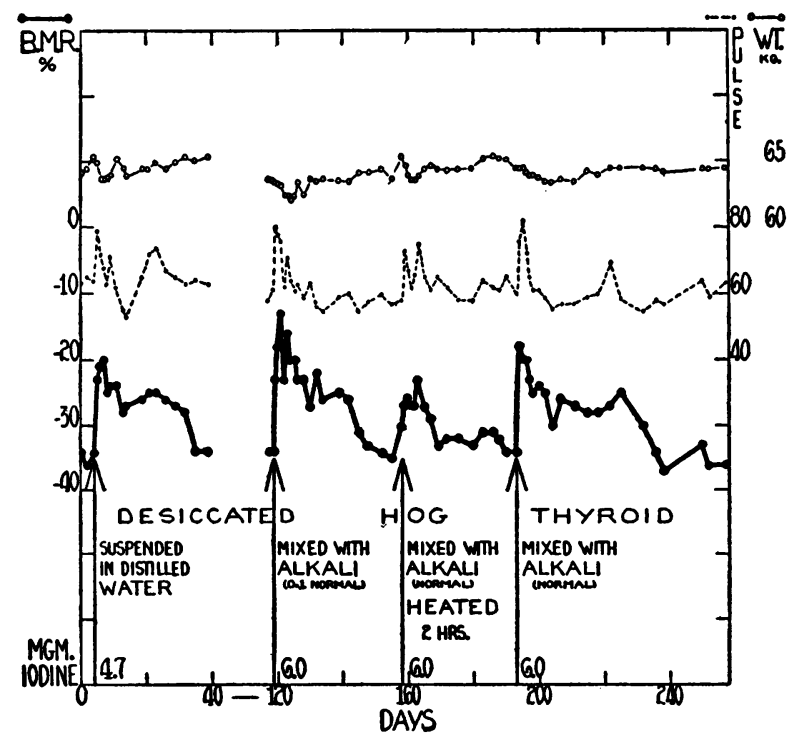

Fig. 4. Mrs. A. R. Lab. No. 1000. Also Showing the Comparative Effects of the Oral Administration of Desiccated Hog Thyroid Suspended in Distilled Water, and Mixed with Alkali, with aNd WITHOUT HEATING 


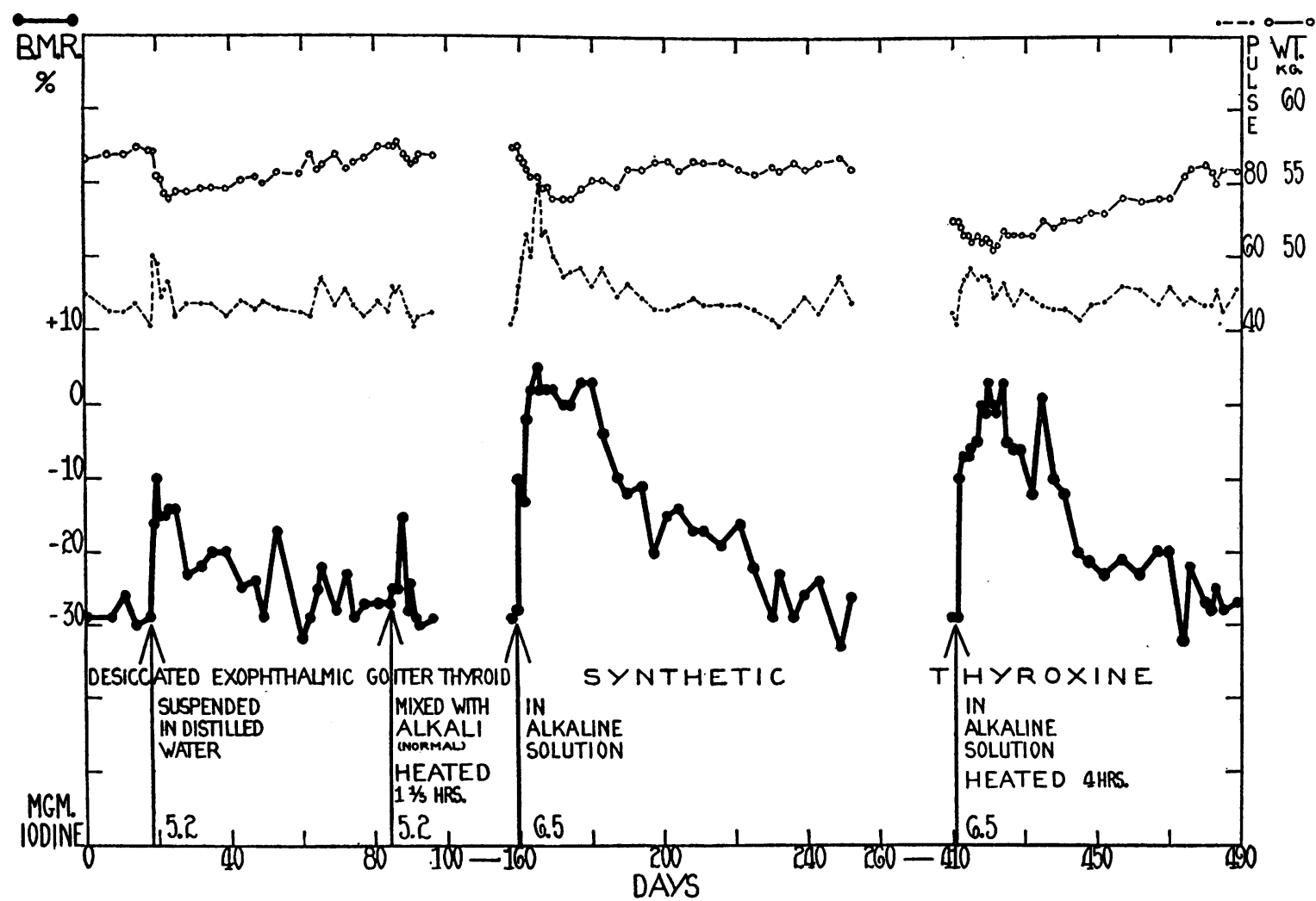

Fig. 5. Miss R. G. Lab. No. 2933. Comparative Effects of the Oral Administration of Desiccated Exophthalmic Goiter Thyroid Suspended in Distilled Water and Heated with Alkali: also of Thyoxine in Alkaline Solution, with and without Heating

Although more data are desirable on this point, they are sufficient to show that in order to produce the marked loss of activity reported above, the presence of alkali is necessary.

\section{Effect of heating thyroxine with alkali}

It may be seen from Tables I and II and Figures 5 and 11 that thyroxine apparently loses no activity as a result of heating with normal sodium hydroxide for four and four and three-quarter hours respectively.

\section{COMMENT}

There are at least four possible explanations for these observations.

1. Although only a small portion of the iodine in the thyroid may be present as thyroxine, the activity of thyroxine may be greatly enhanced by the form or combination in which it occurs and one or both of these may be altered by heating with alkali.

2. Only a portion of the calorigenic activity of desiccated thyroid may be caused by the thyroxine in it and the other iodine compound or compounds in the gland which affect metabolism may be destroyed by heating with alkali.

3. Thyroxine in its natural combination may be more susceptible to destruction by heating with alkali than the free amino-acid.

4. "Thyroxine as 'isolated" may be formed "as an artefact by the action of the rather drastic method of isolation of the active principle," Harington (10). (Apparently disproved by Harington and Salter (11).)

Any combination of these various factors may be involved. Thus, heating with alkali may reduce activity both by destroying the natural form or combination of 'thyroxine and by destroying or reducing the activity of other compounds in the gland which possess activity.

In view of the recent work of Foster, Palmer and Leland (12) on the calorigenic potencies of 1- and dl-thyroxine, it is necessary to consider the possibility that the loss of activity produced by 


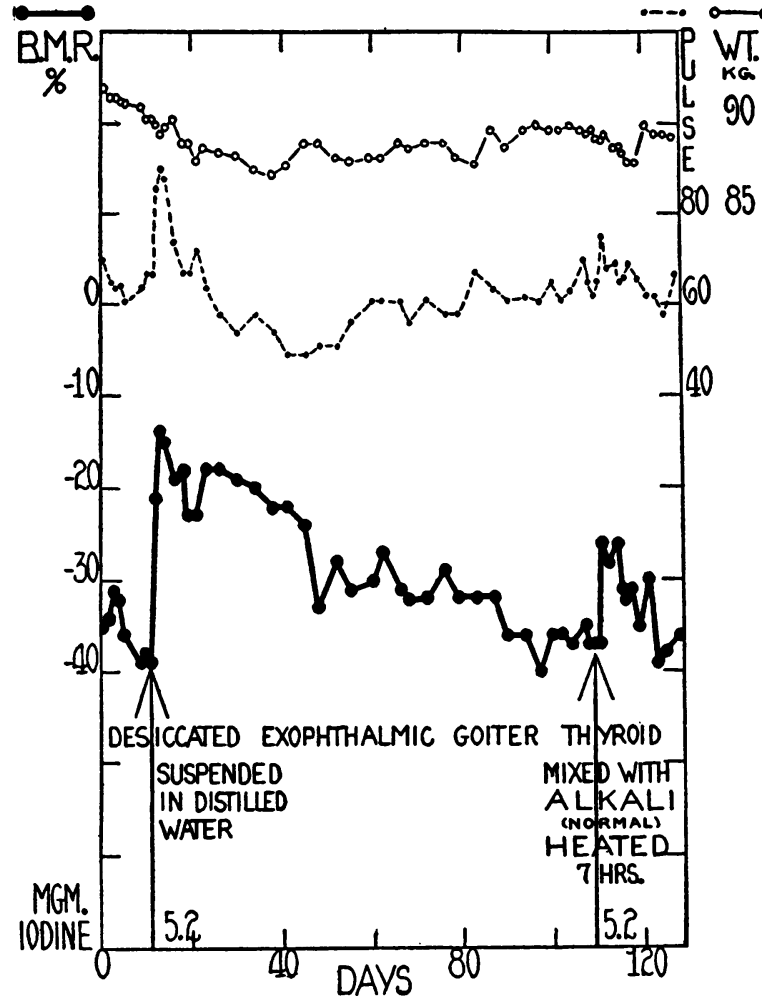

Fig. 6. Mrs. M. J. Lab. No. 3221. Comparative Effects of the Oral Administration of Desiccated Exophthalmic GoIter ThyroId SUSPENDEd IN Distilled Water and Heated with Alkali

heating desiccated thyroid with alkali may be due to racemization of the naturally occurring 1-thyroxine. Using 1-thyroxine obtained by the proteolytic digestion of fresh and desiccated thyroid, they found it to be twice as potent as the racemic form in the guinea pig. Gaddum (13), using material obtained by resolution of dl-thyroxine into its two optically active isomers, found 1-thyroxine to be from one and one-half to three times as potent as d-thyroxine in the rat. However, too few data are presented to warrant quantitative deductions. Salter, Lerman and Means (14), using material obtained by Harington (15) in the same manner as that supplied to Gaddum, reported the two isomers to possess the same activity in man.

An analysis of our results suggests that the loss of activity was greater than could be accounted for by racemization alone. Assuming that all of the calorigenic potency of desiccated thyroid is due to the thyroxine it contains, complete racemization of the thyroxine should destroy half of the activity on the basis of the figures of Foster, Palmer and Leland (12). Our smallest figure for loss of activity, namely that based on the number of points the metabolism changed, shows a reduction of 60 per cent as a result of heating with alkali, whereas that based on extra calories shows a reduction of 80 per cent. We did not carry out thyroxine determinations on the hydrolyzed samples which were administered and, therefore, do not know how much was split off. Since the loss of activity was produced with much less alkali and with a much shorter period of hydrolysis than Leland and Foster (7) found necessary to cause maximum separation of thyroxine, it would appear probable that the racemization in our experiments was not complete. If this deduction be correct, we produced greater loss of activity with incomplete racemization than would be accounted for by complete racemization on the basis of the figures of Foster et al. (12).

In considering further the work of Foster, Palmer and Leland, it is of interest to determine

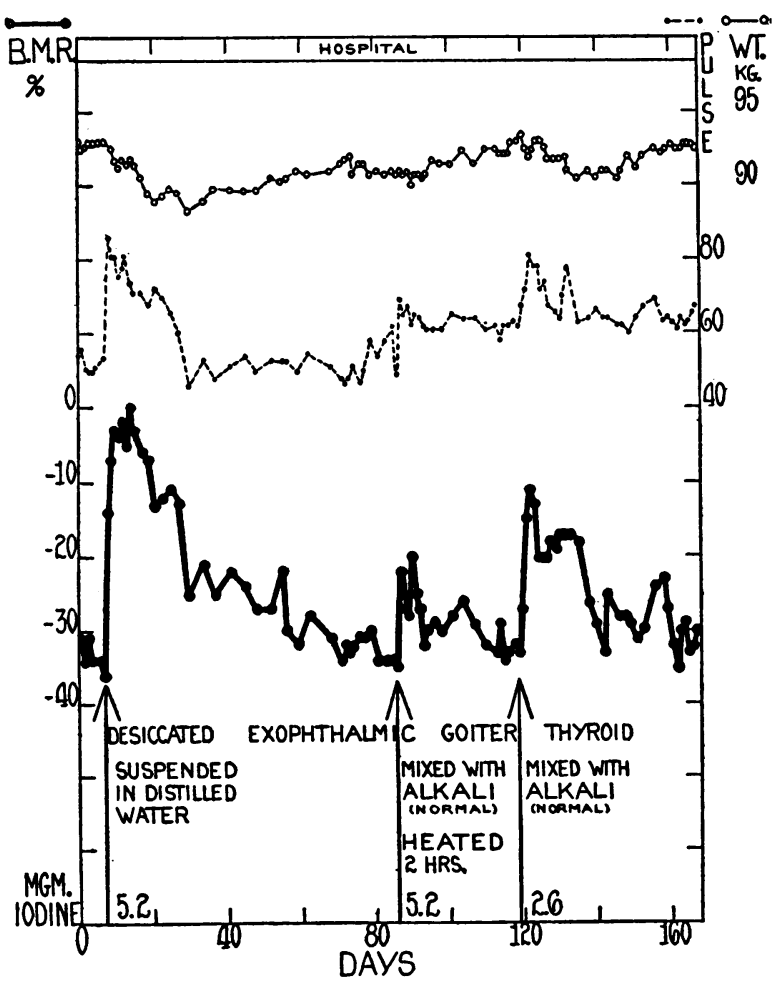

Fig. 7. Mrs. M. W. Comparative Effects of the Oral Administration of Desiccated Exophthalmic Goiter Thyroid Suspended in Distilled Water, and Mixed with Alkali, with and without Heating 


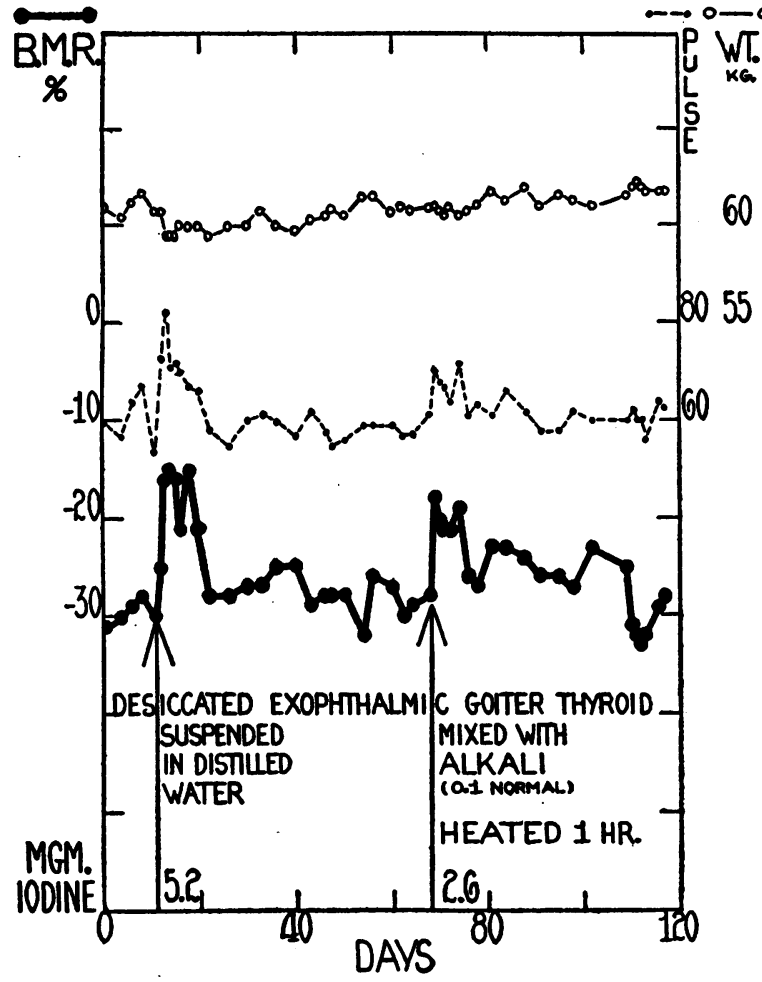

Fig. 8. Mrs. M. S. Lab. No. 3100. Comparative Effects of the Oral Administration of Desiccated Exophthalmic Goiter Thyroid Suspended in Distilled Water and Heated with Weak Alkali

whether heating with alkali reduces the activity of thyroid to that of the thyroxine which it contains. The calculations which follow are based, of course, on the activity of racemic thyroxine. In four of the patients (Mrs. M. M., Mrs. M. K., Mrs. A. R. and Miss R. G.) the effect of administering thyroxine by mouth in alkaline solution has been compared with that of giving desiccated thyroid suspended in distilled water and desiccated thyroid after heating with alkali (Table III). This comparison in the same patients gives results almost the same as those in Table II, in which two of the oral administrations and three of the intravenous administrations of thyroxine in alkaline solution were in patients who did not receive thyroid which had been heated with alkali. It may be seen that, on the average, for every $6.5 \mathrm{mgm}$. of iodine administered by mouth in the form of thyroxine in allkaline solution the basal metabolism rose 23 points (from minus 32 per cent to minus 9 per cent) and 10,340 excess calories were produced; whereas for every $6.5 \mathrm{mgm}$. of iodine given in the form of desiccated thyroid which had been heated with alkali, the basal metabolism rose 8 points (from minus 32 per cent to minus 24 per cent) and 1,210 excess calories were produced. When the thyroid was given suspended in distilled water the corresponding figures were 20 points and 6,070 excess calories respectively. In other words, per milligram of iodine, thyroxine in alkaline solution produced about three times as much increase in basal metabolism and about eight and one-half times as many excess calories as desiccated thyroid which had been heated with alkali. On the basis of the number of points increase in basal metabolism, heating with alkali reduces the calorigenic activity of desiccated thyroid nearly to the level that would be predicted from the Leland and Foster figures (7) for the percentage of iodine present in the form of thyroxine, assuming that heating with alkali reduces the activity of the dried gland to that of the thyroxine which it con-

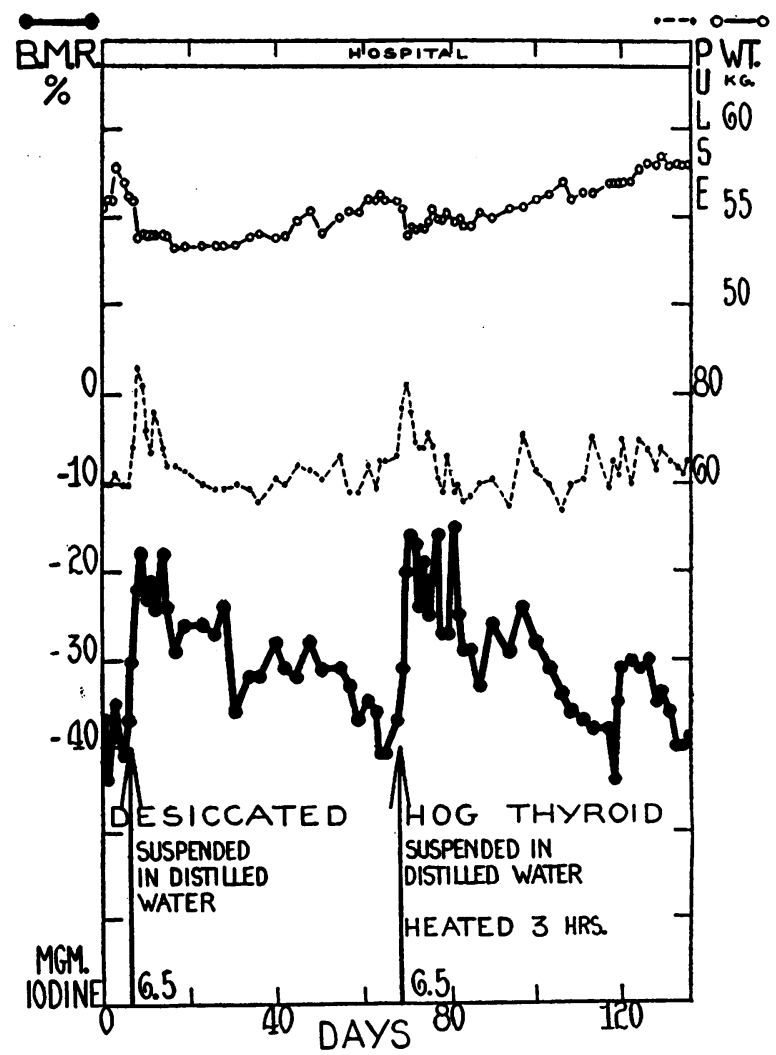

Fig. 9. Miss E. Del. Comparative Effects of the Oral Administration of Desiccated Hog Thyroid Suspended in Distilled Water, with aNd without HEATING 


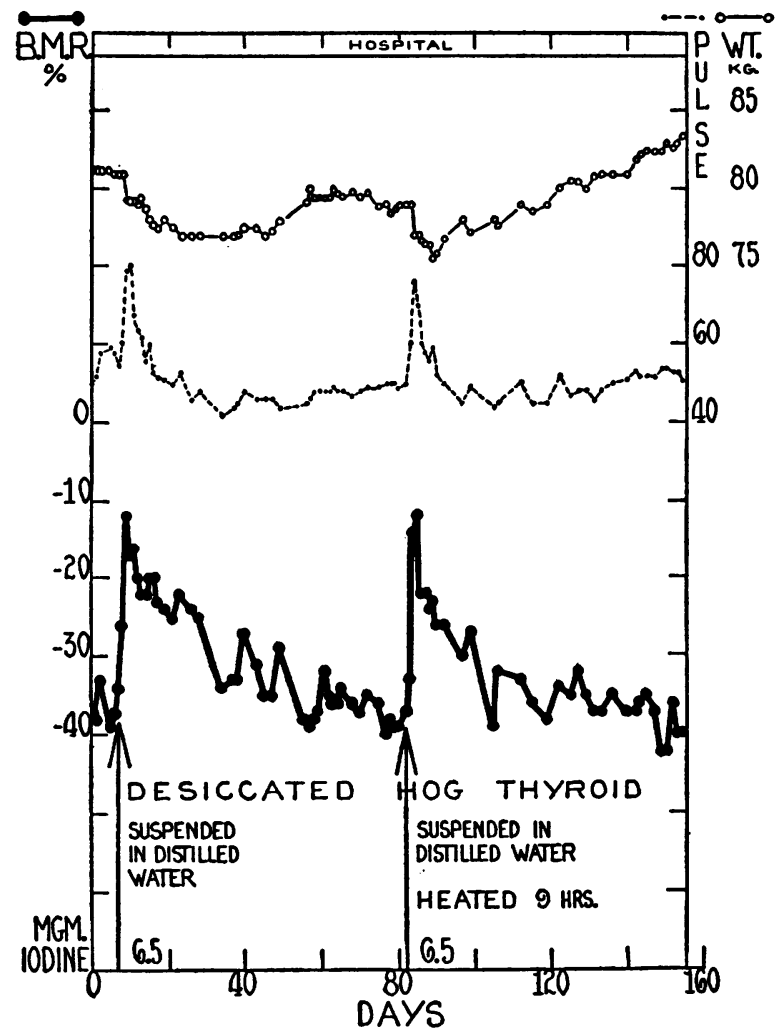

Fig. 10. Mrs. B. L. Also Showing the Comparative Effects of the Oral Administration of Desiccated Hog Thyroid Suspended in Distilled Water, WITH AND WITHOUT HEATING

tains. On the basis of extra calories, the activity is reduced to a lower level than would be predicted. As already pointed out, this reduction occurs with much less alkali than called for by the Leland and Foster method for extraction of thyroxine from the thyroid. They used $100 \mathrm{cc}$. of $2 \mathrm{~N}$ sodium hydroxide per 1.25 grams of dried gland containing probably from 3 to $4 \mathrm{mgm}$. of iodine. These observations suggest the possibility that the activity of thyroxine may be enhanced by its natural combination.

The effect of heating desiccated thyroid with alkali has some bearing on the suggestion advanced by Harington and Randall (16) and by Gutman, Benedict and Palmer (17) that, for pharmaceutic purposes, desiccated thyroid should be standardized in terms of thyroxine rather than in terms of total organic iodine. Harington and Randall (16), on the assumption that after four hours hydrolysis with sodium hydroxide the portion of the iodine insoluble in acid represents thy- roxine iodine, concluded that the iodine in the thyroid is about equally divided between diiodotyrosine and thyroxine: while Gutman and his associates (18), using the butyl alcohol extraction method of Leland and Foster (7) (which included a longer period of alkaline hydrolysis), found that about twenty-five per cent was present as thyroxine, although the actual percentage varied in different glands. Using guinea pigs for assay, Palmer and Leland (19) found calorigenic activity proportional to thyroxine rather than to total iodine.

Regardless of the explanation of our observations, it becomes apparent at once that the method used by all investigators for isolation of the active principle from the thyroid, namely hydrolysis with alkali, destroys most of the gland's activity. Indeed, the low yield of crystalline thyroxine from desiccated thyroid has always been one of the most serious handicaps to a systematic study of its properties. From three tons of hog thyroid Kendall (20) obtained thirty-three grams of thyroxine. By another method, Harington (10) was able at one time to obtain a total yield of 0.125 per cent of thyroxine from a preparation of desic-

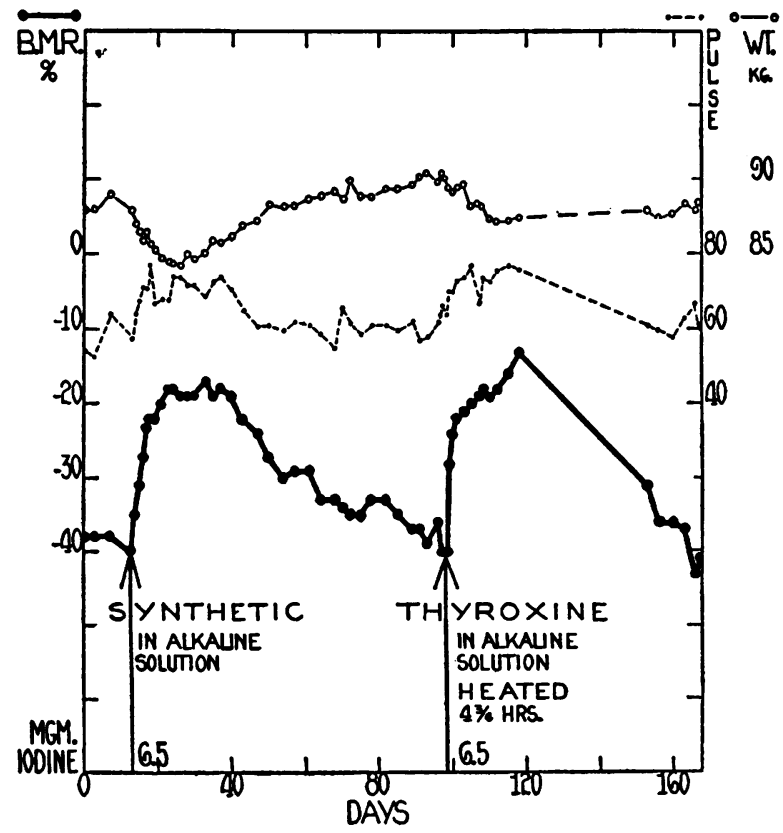

Fig. 11. Mrs. C. F. Lab. No. 2998. Comparative Effects of the Oral Administration of Thyroxine in Alkaline Solution, with and without Heating 
cated thyroid gland containing 0.5 per cent of iodine. The low yields frequently observed by these two investigators may be attributed to loss or destruction of thyroxine or to the presence of only a small quantity of iodine in the form of thyroxine to begin with.

\section{SUMMARY}

After heating with approximately normal sodium hydroxide for from one to seven hours, desiccated thyroid loses about three-fifths of its calorigenic activity on the basis of the amount of increase in basal metabolism, and about fourfifths of it on the basis of the number of extra calories produced. The activity of racemic thyroxine is not significantly affected by the same procedure. The effect of desiccated thyroid is not altered when it is heated with distilled water or when it is allowed to stand in normal alkali without heating, showing that a combination of both heat and alkali are necessary to produce loss of activity.

When given by mouth in alkaline solution, thyroxine produces, per milligram of iodine, about three times as much increase in basal metabolism and about eight and one-half times as many extra calories as desiccated thyroid which has been heated with alkali.

These observations show that the procedure common to all methods for isolation of thyroxine from the thyroid (namely, heating with alkali) destroys most of the gland's activity. They have an important bearing on the form in which iodine occurs in the gland and on the methods of standardizing desiccated thyroid.

\section{BIBLIOGRAPHY}

1. Thompson, W. O., Nadler, S. B., Taylor, S. G., III, and Thompson, P. K., The calorigenic action of various thyroid derivatives. J. Clin. Invest. (Proc.), 1934, 13, 690.

2. Thompson, W. O., Thompson, P. K., Taylor, S. G., III, Nadler, S. B., and Dickie, L. F. N., The pharmacology of the thyroid in man. J. A. M. A., 1935, 104, 972.

3. Roos, E., Ueber die Wirkung des Thyrojodins. Ztschr. f. physiol. Chem., 1896, 22, 18.

4. Cameron, A. T., and Carmichael, J., An attempt to evaluate thyroid preparations, utilizing their effect on growth-rate and production of organhypertrophy in the young white rat. Tr. Roy. Soc. Canada, 1926, 20, 3, section v, 1.

5. Oswald, A., Neue Beiträge zur Kenntnis der Bindung des Jods im Jodthyreoglobulin nebst einigen Bemerkungen über das Jodothyrin. I, II. Arch. f. exper. Path. u. Pharmakol., 1909, 60, 115; 1910, 63, 263.

6. Kendall, E. C., and Simonsen, D. G., Seasonal variations in the iodine and thyroxine content of the thyroid gland. J. Biol. Chem., 1928, 80, 357.

7. Leland, J. P., and Foster, G. L., A method for the determination of thyroxine in the thyroid. J. Biol. Chem., 1932, 95, 165.

8. Thompson, W. O., Thompson, P. K., Brailey, A. G., and Cohen, A. C., The calorigenetic action of thyroxin at different levels of basal metabolism in myxedema. J. Clin. Invest., 1929, 7, 437.

9. Thompson, W. O., Thompson, P. K., Dickie, L. F. N., and Alper, J. M., Effect of alkali on the absorption of thyroxine from the gastro-intestinal tract with a note on the comparative effects of synthetic and "natural" thyroxine injected intravenously. Arch. Int. Med., 1933, 52, 809.

10. Harington, C. R., The Thyroid Gland, Its Chemistry and Physiology. Oxford University Press, London, 1933.

11. Harington, C. R., and Salter, W. T., The isolation of $l$-thyroxine from the thyroid gland by the action of proteolytic enzymes. Biochem. J., 1930, 24, 456.

12. Foster, G. L., Palmer, W. W., and Leland, J. P., A comparison of the calorigenic potencies of $l$-thyroxine, $d l$-thyroxine, and thyroid gland, with a note on the thyroxine content of the acid-soluble fraction of the peptic digest of thyroid protein. J. Biol. Chem., 1936, 115, 467.

13. Gaddum, J. H., Quantitative observations on thyroxine and allied substances. II. Effects on the oxygen consumption of rats. J. Physiol., 1930, 68, 383.

14. Salter, W. T., Lerman, J., and Means, J. H., The calorigenic action of D- and L-thyroxin. J. Clin. Invest., 1935, 14, 37.

15. Harington, C. R., Resolution of $d l$-thyroxine. Biochem. J., 1928, 22, 1429.

16. Harington, C. R., and Randall, S. S., The chemical assay of thyroid gland. Quart. J. Pharm. and Pharmacol., 1929, 2, 501.

17. Gutman, A. B., Benedict, E. M., and Palmer, W. W., Assay of thyroid by chemical estimation of the thyroxine content. Proc. Soc. Exper. Biol. and Med., 1932, 29, 1198.

18. Gutman, A. B., Benedict, E. M., Baxter, B., and Palmer, W. W., The effect of administration of iodine on the total iodine, inorganic iodine, and thyroxine content of the pathological thyroid gland. J. Biol. Chem., 1932, 97, 303.

19. Palmer, W. W., and Leland, J. P., Comparative calorigenic action of normal and pathological thyroid glands administered in equi-thyroxine doses. J. Clin. Invest., 1935, 14, 619.

20. Kendall, E. C., Isolation of the iodine compound which occurs in the thyroid. J. Biol. Chem., 1919, $39,125$. 